\title{
A FORMA ÓBVIA: POESIA E PINTURA EM LUCINDA PERSONA
}

\section{THE OBVIOUS FORM: POETRY AND PAINTING IN LUCINDA PERSONA}

\author{
Célia Maria Domingues da Rocha REIS ${ }^{110}$ \\ Renato Cardoso de MORAES ${ }^{111}$
}

\begin{abstract}
RESUMO: Lucinda Nogueira Persona, escritora paranaense radicada em Mato Grosso, premiada pela União Brasileira de Escritores, apresenta em sua obra muitos recursos plástico-pictóricos, tanto em verso como em prosa. No presente estudo, investigamos algumas relações entre os diferentes sistemas de representação, poesia e pintura, encontrados no poema "Ovos à vista", da obra Tempo comum (2009), procurando identificar soluções estético-discursivas que resultaram na plasticidade do literário, no modo como as palavras tomaram corpo, apropriaram-se dos elementos visuais, pontos, traços, sombras, contrastes, luz, cor, criando poesia.
\end{abstract}

PALAVRAS-CHAVE: Lucinda Nogueira Persona; Literatura brasileira mato-grossense; Literatura e pintura.

\begin{abstract}
Lucinda Nogueira Persona, award-winning writer by União Brasileira de Escritores (UBE), uses in her work many plasticpictorial features, both in verse and prose. In the present study we investigated some relationships between these different systems of representation, poetry and painting, found in the poem "Ovos à vista", from the work Tempo Comum (2009) seeking to identify aestheticdiscursive solutions, which resulted in plasticity of the literary in the way the words took shape, in the way they took hold of the visual elements, dots, lines, shadows, contrasts, light and color creating poetry.
\end{abstract}

KEYWORDS: Lucinda Nogueira Persona; Brazilian literature (Mato Grosso state); Literature and painting.

Lucinda Nogueira Persona, escritora paranaense radicada há algumas décadas em Mato Grosso, apresenta em sua obra muitos recursos plástico-pictóricos, tais como

110 Docente do Curso de Graduação em Letras. Docente e coordenadora do Programa de Pós-Graduação em Estudos de Linguagem, do Instituto de Linguagens, da Universidade Federal de Mato Grosso (UFMT). CEP 78600-900, Cuiabá, MT, Brasil celiadr@uol.com.br 
luz, cor, volume, contraste, tanto em verso como em prosa. Motivados pela singularidade da produção, empenhamo-nos em compreender esse processo de criação por meio da investigação de algumas correlações entre literatura e pintura, identificando soluções discursivas, estilísticas, que resultam na plasticidade do literário, no poema "Ovos à vista", da obra Tempo comum (2009) .

Sabendo que o artista plástico, poeta, portanto, vivencia a experiência da expressão ao condensar num suporte a carga emotiva dos lampejos de suas visões, verificamos, nesse estudo do literário no espaço-tempo, como, pela palavra, pela linguagem, as imagens tomam corpo; como apropriam-se dos elementos visuais, desenham-se de pontos, de traços; vingam das sombras; modelam-se sob a luz; cobrem de cor a nudez de sua superfície.

No percurso teórico da análise tomaremos alguns eixos desenvolvidos por Aguinaldo Gonçalves no ensaio denominado "As três instâncias de leitura do quadro 'A Negra' de Tarsila do Amaral", da obra Signos (em) cena: ensaios (2010), que, em síntese, consiste na percepção e compreensão de três instâncias sígnicas: "o signo ligado ao referente", o "signo elevado à condição de símbolo" e o signo como "signo complexo da arte [...]" (2010, p. 83), o que rompe com "referentes preconcebidos ou de arquétipos estereotipados"; que recusa a compreensão do signo em "condição biunívoca" (2010, p. 83 e p. 11).

Para o estudo específico do aspecto pictórico, foi oportuno o uso de princípios importantes das artes plásticas contidos em Universos da arte (1987), de Fayga Ostrower, trabalho de referência à pesquisa fronteiriça das poéticas verbo-visuais.

No que respeita à criação, entendemos com Ostrower que as articulações entre forma e conteúdo não se estabelecem ao acaso, mas por conexões estabelecidas pelo fruidor. É o fruidor que relaciona os fenômenos entre si e os vincula a ele mesmo. As relações e vínculos são orientados pelo que comportam os níveis mais profundos de suas emoções, "expectativas, desejos, medos, e sobretudo de acordo com uma atitude do [...] ser mais íntimo, uma ordenação interior" (OSTROWER, 1987, p. 9), subterrâneo múltiplo que compõe uma unidade na compreensão da obra.

Nessa esteira, Gonçalves aponta o interessante fenômeno que integra ato criador e obra. No ato criador, os elementos são "atraídos" por uma força centrípeta (“ordenação interior”) que os vincula e, na obra, estes são "contidos” por essa mesma força. Daí o crítico afirmar que 
Pluralidade aqui [na obra de arte] não possui o sentido de diversidade multifacetada, ao contrário, traz em si a consciência de síntese, de coerência, de direção centrípeta das imagens e das relações que fazem da obra [A Negra, no caso] um objeto harmônico e incômodo, pelo movimento dos sentidos que suas figuras instauram (GONÇALVES, 2010, p. 80).

As formas constituem os loci conformadores da visão e entendimento do mundo. O estado de "tensão psíquica" do artista se objetiva em "forma física", razão pela qual há reciprocidade na apreciação da obra: ela é capaz de nos afetar em termos de "intensidade, emocional e intelectual, [sem a qual] não haveria como se saber algo sobre o significado da ação, sobre o conteúdo expressivo da forma" ou ainda sobre os valores que expressa (OSTROWER, 1987, p. 28). É por isso que, ante uma obra de arte, ante "um universo de categorias plásticas integradas e indivisíveis que provocam uma dinâmica produtora de relações de sentido" (GONÇALVES, 2010, p. 20), o observador atento pode, por exemplo, sintetizar uma instância como disfórica, ainda que os conteúdos, numa primeira impressão, apontem para um efeito eufórico.

Vejamos agora o poema:

\section{OVOS À VISTA}

Não há paz nos meus olhos

De novo, meu alvo:

ovos à vista

(e mãos à obra)

Sim, são ovos os que ali estão

na obviedade de sua forma

na avidez de sua elipse

o que se vê por fora

e não é muito

Há uma dúzia deles

sempre do mesmo modo

gêmeos

já mortos em cada caso

(deixo isso às claras)

Ovos

passo horas

enfrentando

o caos

Um é o outro

um é o outro

um é o outro

Não há nada

de diferente

no que vejo?

(PERSONA, 2009, p. 56). 
No exercício da sensibilidade, da exploração das amplas possibilidades de contato com este poema, submetêmo-lo a indagações primárias (intuitiva ou conscientemente): se se estrutura em estrofes; se os versos são regulares ou se há algum aspecto figural na sua conformação; se aparece inteiro na página ou estende-se para além dela. Há uma necessidade de tomar pé, obtendo uma apreensão inicial dos aspectos formais do poema: seu tamanho, sua estrutura corpórea; se o momento é propício para uma primeira leitura; se o tempo disponível será suficiente para uma primeira impressão do que viria a ser o todo etc. Ao adquirimos um livro, podemos observar os aspectos de sua configuração, dimensões, peso, a arte da capa, o tipo de papel do miolo, o tipo de letra etc., leituras que se somarão à impressão da obra como um todo. Esse contato com a obra de arte, a percepção dessas realidades, se feitos em primeira mão, podem atuar como um pré-aquecimento, um abrir de janelas para a poesia.

Assim, para a análise do poema "Ovos à vista", buscamos o fenômeno da linguagem como uma necessidade de (re)conhecer as instâncias do processo criador e da recriação da obra de arte pela apreensão do momento da comunicação referencial do signo, ligado às coisas do mundo; das possíveis leituras simbólicas; de como se dá o processo ou o seu reconhecimento; de como ou por que determinada obra de arte alcança grau elevado de poeticidade, ou de modulação. Ainda, como a figuratividade do texto associada a elementos como os "aspectos fônicos do trabalho literário; os problemas de significado no interior da trama poética e integração de som e sentido num todo inseparável” (JAKOBSON, 1983, p. 485) contribuem para a síntese do poema como um "signo complexo".

Na leitura do poema "Ovos à vista", deparamo-nos imediatamente com as potencialidades significativas da palavra Ovos. Paul Henle diz que a palavra é "um signo 'imediato' de seu sentido literal, e um signo 'mediato' de seu sentido figurativo" (apud RICOEUR, 2005, p. 289). E, lembrando Hjelmslev,

[...] o signo é uma grandeza de duas faces, uma cabeça de Janus com perspectiva dos dois lados, com efeito nas duas direções: 'para o exterior', na direção da substância da expressão, 'para o interior', na direção da substância do conteúdo. (2009, p. 62). 
À luz desses conceitos, algumas imagens e seus significados começam a tomar corpo em nosso espírito. De fato, ante a palavra "Ovos", sofremos a força imediata do signo tentando ligar-nos a um contexto ainda em suspensão. Em tempo, as "modalidades de enfoque", as "ordenações de campo" e "de grupo", discutidas por Ostrower (1987, p. 79-90), afetam-nos: pensamos em \{“ovo" comida fome\}; pensamos em \{“ovo" semente fruto\}. Dessas primeiras configurações mentais, outras ordenações, outras relações de sentido se fazem presentes. Adiantando um pouco, veremos que, vencido o engodo do índice referencial, a função metalinguística revelar-se-á como dominante na estrutura do poema.

A pluralidade de sentidos suscitada pelo poema parece originar-se da metáfora do rompimento da fina casca do ovo, figura enfaticamente expressa pela conformação visual do texto que, em seu aspecto externo, já apresenta dois segmentos distintos. Observa-se um deslocamento horizontal de boa parte da base da estrofe, que desliza em bloco para a direita, sem, contudo, desmembrar-se em outra estrofe. Esse novo segmento recebe como que uma credencial, um subtítulo / Ovos /, que o vincula ao bloco maior, ao bloco superior. Há uma agudeza na construção. Os versos irregulares do segmento superior desenham como que fractais de uma casca de ovo quebrada, contrastando com o inferior, mais liso, estreito e fluido, modulado numa linearidade vertical. A figura representa um gesto comum da culinária: o ovo que, tendo sido cuidadosamente quebrado numa das extremidades, é levantado e lentamente inclinado para que somente a clara escoe, retendo a gema no invólucro quase intacto.

Somente uma força interior, uma tensão angulosa bicando esse simulacro ovoide pode romper e afastar as crostas para o derramamento da poesia. Pensamos no verso dentro dos parênteses

\section{(deixo isso às claras)}

forçando a abertura dessa concha bivalve para que a poesia flua numa nova direção e sentido, numa "trajetória [vertical] rumo à interiorização" (GONÇALVES, 1994, p. 243), fazendo com que o poema desprenda-se da página e constitua-se presença palpável.

Em se tratando desse signo singular, "ovos", de significações plurais em expressão e conteúdo, não há como evitar uma rápida passagem pelo simbólico. Sendo o ovo "um símbolo universal [que se] explica por si mesmo" (CHEVALIER; 
GEERBRANT, 1993, p. 672), relevamos, por exemplo, a fragilidade do ovo, que o torna objeto de cuidados; sua forma inteira e justa; seu pendor ao repouso, revelador do "plano inclinado"112, que bem o soube Clarice Lispector; e o ovo como emblema de renovação e de manifestação. Sabe-se que essas associações são bastante fecundas e estão assimiladas em diversas culturas, de modo que não há como negar seus reflexos na produção artística e, naturalmente, em nossa análise.

Dissemos anteriormente do domínio da função metalinguística no poema. O texto de Lucinda Persona se estrutura como uma manifestação poética do ato criador. Além da sua elaboração formal, há outros índices que apontam para tanto. Numa releitura, encontramos no título a indutora temática $O v o s$, que, em primeira instância, apela à referencialidade, contexto essencial para a trama poética proposta. Prosseguindo, vemos o primeiro verso / Não há paz nos meus olhos /: eis o que move o artista, a necessidade de modular "tensões psíquicas" (OSTROWER, 1987, p. 27) em ordenações objetivas, no caso, o poema, objeto de um anseio, como se observa em: / De novo, meu alvo: /. Há uma necessidade quase obsessiva que se conjuga à convocação para o poético: / Não há paz nos meus olhos /. Como instrumento sensível integrado à poesia, o artista só descansa quando da resolução de sua obra de arte. Não obstante o compromisso, há disposição para o fazer poético, concentrado em / (e mãos à obra) /. E já supomos que essa "obra" não consiste em fritar ovos ou bater claras em neve. Mais adiante, os versos homologam a previsão: / (deixo isso às claras) / e também: / passo horas / enfrentando / o caos /. Descartamos, então, o eventual pensamento de horas em trabalho culinário, exceto se recorrermos à expressão "culinária poética"113, muito bem utilizada por Marta Cocco. As / [...] horas / dedicadas ao embate constituem o tempo despendido no labor mental para ordenação da massa informe do pensamento em materializações coerentes, tanto em formas de conteúdo como em formas de expressão, das quais se constitui a linguagem (HJELMSLEV, 2009). De maneira que, pela forma, a

112 Expressão usada por Clarice Lispector no conto $O$ ovo e a galinha: "O ovo desnuda a cozinha. Faz da mesa um plano inclinado" (In: Felicidade clandestina. Rio de Janeiro: Francisco Alves, 1994. p. 57).

113 A partir do espaço doméstico, a cozinha, os alimentos, a autora Marta Cocco, em Culinária poética em Lucinda Persona: um banquete de imagens estabelece relações de modo a compor os pratos: salada de couve, salada de alface, salada de tomate, cebola frita, arroz e uma sopa de ervilhas. 
poeta alcança a resolução de seu questionamento: / Não há nada / de diferente / no que vejo? /. Pela forma, o artista supera o aspecto biunívoco do signo e alça o signo complexo.

Há um ideal mimético de simplificação da forma, manifesta nos versos / o que se vê por fora / e não é muito /. Tal pensamento se confirma pelo garimpo lexical inverso: as palavras valorizadas são as de uso cotidiano, palavras comuns, de fácil locução e, em maioria, mono ou dissilábicas - "paz”, "meu”, "novo”, “mãos”, “ali”, “sim”, "vê", "caos" etc. Apenas umas poucas palavras menos usuais e densas foram incluídas

na obviedade de sua forma na avidez de sua elipse

“Obviedade”, "avidez", “elipse”. A superfície do ovo não mostra, sob olhar despreocupado, incrustações, acidentes, nervuras, nem vibrações de cor em sua forma arredondada e previsível. Mas a metáfora construída lhes dá essa conformação: pelo uso inaudito desses vocábulos, uma impertinência semântica que resulta da atribuição de qualificativos impróprios às peculiaridades do objeto ovo; pelo efeito sonoro-rítmico: ovo óbvio, ávido "em sua elipse”, apresentado em versos eneassílabos dispostos em paralelismo sintático, dos quais se destacam as homorgânicas $/ b v v d /$; o uso reiterado de encontros consonantais / $b v$ ps/ e constritivas sonoras; assonância da vogal anterior $/ i /$, que mostram o seu estreitamento, sua pequenez.

No todo do poema, destaca-se a similitude formal e única entre estes dois versos: / (e mãos à obra) / e / (deixo isso às claras) /. Os valores sígnicos desses parênteses são fundamentais para a percepção do movimento dos elementos constituintes da imagem, que se orientam a partir de forças externas e internas. No verso / (e mãos à obra) /, conquanto forças internas atuem, enxergamos as mãos em concha como uma metáfora, uma tensão no sentido de compressão, que presentifica ou materializa a força externa demandada pelos atos de compor, realizar e modular (GONÇALVES, 2010, p. 27-28). Já no verso / (deixo isso às claras) /, como vimos anteriormente, o recurso promove um efeito inverso: a tensão da expressão é valorizada por um movimento de expansão, de abertura.

Retomemos a palavra "ovos”, na sua incidência sonora e gráfica. Foi uma feliz escolha. Ela é dotada de eixos. Nasceu adaptada para girar, rolar autônoma, leve e solta, com seus mistérios sibilantes. A percepção e uso desses aspectos da forma corroboram 
para a inteireza da obra e estão em acordo com o dito de Jakobson sobre a "integridade de entonação" (1983, p. 486) na poética atual. Notamos, na oralidade dos versos, uma entonação possível, que acentua determinados sons:

Não há pazz nos meus olhos

De novo, meu alvo:

ovos à vista

(e mããos à obra)

Ao estender esse critério para o poema todo, podemos sentir a vibração promovida pela alternância entre vogais claras/graves como uma metáfora do claro/escuro ou do brilhante/opaco, de algum modo texturizando o que compõe a face visível dos corpos.

Além de evidenciar outras antinomínias, aberto/fechado, morto/vivo, vazio/cheio, igual/diferente, interno/externo, essa texturização parece escapar aos domínios da entonação ao permear todo o texto poético. Signos como "alvo", "obra", “são", “estão”, “forma”, “fora”, “caso", "passo", "horas”, “caos”, colhidos por sua carga expressiva, compõem uma malha de semissímbolos, capazes de içar o poema e conferirlhe o estatuto de obra de arte, pela singularidade, unidade e concretude alcançadas.

Nessa perspectiva, tomamos os versos finais do poema:
Um é o outro
um é o outro
um é o outro
Não há nada
de diferente
no que vejo?

A reiteração enfática dos "um e o outro", não obstante o artigo definido reconheça a distância, revelam o espanto pela monotonia da semelhança, pela ausência de uma autonomia de ser, de completude pela "outridade". Eis o engaste perfeito do signo "nada" que, vazio, numa depreensão imediata, transparente e diluída, porque o "nada" não é, considerando que só pode ser pensado em relação ao ser, convoca novamente, no entanto, a inquietude dos versos iniciais: 
Não há paz nos meus olhos

O poema se consolida como uma metáfora não-trivial, uma metáfora poética, tentativa de redescoberta - "Ovos à vista" - da oposição dos seres entre si, da diferenciação. Isso adensa e amplia sobremaneira a concepção de que este poema se estrutura como expressão poética do ato criador, exposta anteriormente, se refletirmos com Octavio Paz (1976, p.102) que o poema é um modo de devolução, à linguagem, "da sua qualidade metafórica de perceber no uno o outro", de lhe "dar presença", em meio a um mundo que perdeu a noção de si mesmo. Poesia: procura dos outros, procura “interminável, precisamente porque sempre pode começar” (RICOUER, 2005, p. 289). Cada novo recurso de estilo ajustado no seu devido lugar e função valida e acentua os demais, concorrendo para que a poesia ludibrie o plano e plasme na luz toda a sua plenitude, para que ocupe o espaço em quadridimensão, com todo seu volume e tempo, como um ovo mesmo ovo: um ovo-poema.

\section{REFERÊNCIAS}

CHEVAlIER, J.; GHEERBRANT, A. Dicionário de símbolos. Trad.de Vera da Costa e Silva et al. Rio de Janeiro: J. Olympio, 1993.

COCCO, M. H. Culinária poética em Lucinda Persona: um banquete de imagens. In: LEITE, M. C. S. (Org.). Mapas da mina: estudos de literatura em Mato Grosso. Cuiabá: Cathedral Publicações, 2005. p. 141-156.

GONÇALVES, A. Laokoon revisitado: Relações Homológicas entre Texto e Imagem. São Paulo: EDUSP, 1994.

Signos (em) cena: ensaios - variações acerca de modulação no trabalho de arte: fragmentos críticos. Cotia, SP: Ateliê, 2010.

HJELMSLEV, L. Prolegômenos a uma teoria da linguagem. São Paulo: Perspectiva, 2009.

JAKOBSON, R. O dominante. Trad. Jorge Wanderley. In: LIMA, L. C. (Org.). Teoria da literatura em suas fontes. Rio de Janeiro: Francisco Alves, 1983. p. 485-491.

LISPECTOR, C. Felicidade clandestina. Rio de Janeiro: Francisco Alves, 1994.

OSTROWER, F. Universos da arte. 24.ed. Rio de Janeiro: Elsevier, 2004.

Criatividade e processos de criação. 6.ed. Petrópolis, RJ: Vozes, 1987.

PAZ, O. Signos em rotação. Org. Celso Lafer e Haroldo de Campos. São Paulo: Perspectiva, 1976.

PERSONA, L. N. Tempo comum. Rio de Janeiro: 7Letras, 2009. 
RICOEUR, P. A metáfora viva. Tradução de Dion Davi Macedo. 2.ed. São Paulo: Edições Loyola, 2005.

Artigo recebido em 29/07/2012 Aceito para publicação em 24/09/2012 